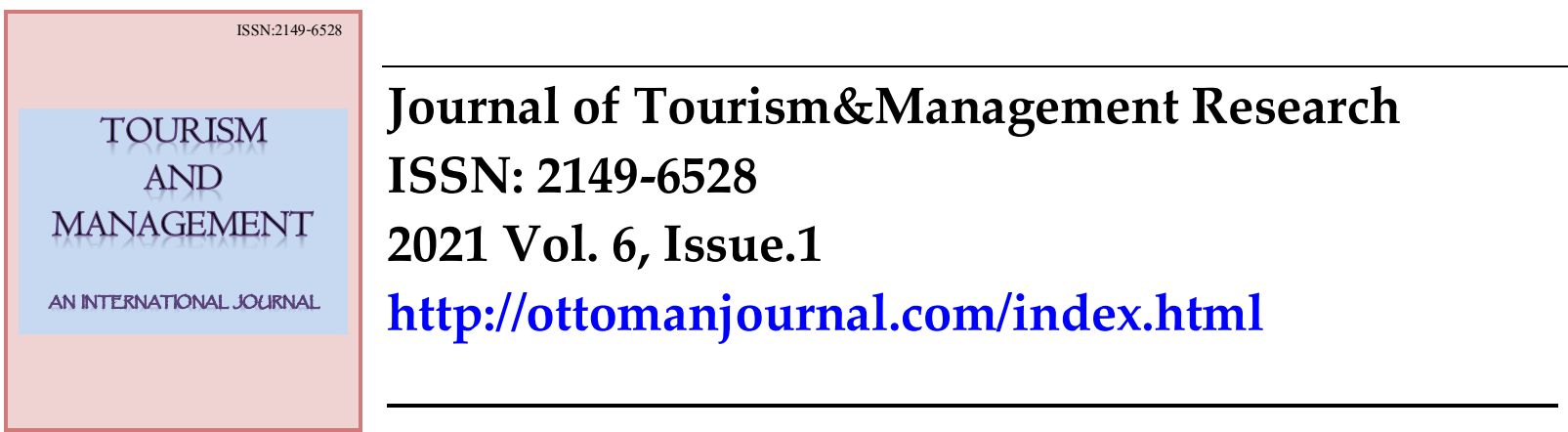

\title{
A Conceptual Study of Proposing a Model to Use Robots in Hospitality Industry based on the Empirical Evidences
}

\begin{abstract}
The aim of this paper is to analyze the development perspectives of robots in the hospitality industry and to draw a research model which may contribute in future reserch. More precisely, the current work examines the intentions of the consumers and employees to use robots on hotel services based on the findings of the related literature. The existing literature indicates that there is a gap due of the lack of academic research and of the fact that robots are used only in a small number of hotels. Recent publications indicate that there is a dichotomy over whether robots can benefit or not the hospitality sector. Based on the findings of the literature review, the authors have moved on with a research model which is going to be used for the case of Greek hotels. Hence, this paper aims on developing a conceptual framework for the intention to use robots from hotels and its impact on the expectations from the service quality of the hotels which use robots. However, this model has not been tested yet. Regarding the value of developing and using the proposed research model, by implementing this model, the academia and the practitioners would be able to understand on which type of hotel the robots would provide a better value. The use of robots on the hospitality industry is something new. This means that there is a lack of consensus over its value and usage along with a lack of a conceptual framework. For this reason, this study helps the academia and practitioners to better understand the contribution of robots in the hospitality industry.
\end{abstract}

Keywords: Hospitality, robots, services, technologies, satisfaction, hotels

JEL Classification: Z32, L83, M10

Submitted: 31/12/2020; Accepted: 15.04.2021

Dimitrios Belias, Assistant Professor. (Corresponding Author). Department of Business

Administation, University of Thessaly, Larissa, Geopolis, 41500, Greece. Tel.+30 6972716980.

Postdoctoral Research Fellow, Core Department, at the National and Kapodistrian University of Athens, Greece.

Email: dbelias@pe.uth.gr 
Labros Vasiliadis, Asst. Professor. Marketing Management, Core Department for National and Kapodistrian University of Athens, Athens 157 72, Greece,

E-mail: labvas@uoa.gr

\section{Introduction}

Tourism is one of the most important components of a country's economy. In particular, Greece is one of the most important destinations for tourism worldwide, while the tourist industry contributes on more than the $25 \%$ of the workforce of the country (direct or indirect). Furthermore, tourism is a key of development for many regions, while during the past years sustainable tourism has paved the way for further growth in rural areas of Greece (Giannoukou \& Beneki, 2018).

A critical element of success on tourism is the use of Information and Communication Technologies, also well known as ICT, from the tourist companies and authorities. Despite of some significant progress made in the use of ICT from Greek tourist companies, the study of the ICT index (ICTReadiness) included in the International Travel and Tourism Competitiveness Index / Travel and Tourism Competitiveness Index (TTCI) concludes that most countries, and in particular Greece, do not fully exploit the potential of technology, though that ICT can become a key source of competitive advantage for tourism (Katou \& Katsouli 2019; Valeri \& Baggio, 2020c).

The use of new technologies and information systems on tourism can occur on many ways, such as the use of CRM software or using social media so to leverage the image and the branding of tourist destinations and organizations (Ivanov, 2020; Kapiki \& Fu, 2015). A recent development has been the case of the use of robots on tourist companies.

Robotics has many different applications both in production - for example automation of production lines - and in services. One particular perspective is on whether robots can replace humans in providing services, in particular tourism services (Kavoura, 2021). The current empirical research and practical experience on hotels that have used robots especially in large hotels - indicates that the use of robots has significant benefits (Ivanov \& Webster, 2017; Tussyadiah \& Park, 2018; Webster, 2019). Robots are effective on their tasks when they are used in routine services such as reception, the cleanliness (housekeeping) and catering services (Belias, 2020a). The use of robots can enhance the quality of service, and therefore customer satisfaction (Salminen \& Milenkovic 2020). In addition, the use of robots in the above services reduces the operating costs of tourist units. Improving the quality of services also has a positive impact on the working environment and thus on job satisfaction (Belias, 2019a; Belias \& Varelas, 2018).

It is important to note that the use of robots on tourist businesses is limited, while limited is also the related academic research and findings. For this reason, this paper will try to fill in the gap by providing a research paradigm on the intentions of the employees and customers to use robots and what are their expectation from the quality of the services that the robots will provide. Hence, this is a conceptual study which presents the past research findings and based on this it proposes a study model for future usage.

\section{Literature Review}

\subsection{Information Systems in Hotels}

Most businesses have adopted an information system. There is no commonly accepted definition of what constitutes an information system, as most definitions are related to the actual domain in which these systems are exploited. However, based on international literature (Kroenke, 1990; Lopes et al., 2017; Wood-Harper et al., 1985) a brief descriptive 
definition of what constitutes an information system can be derived in order to determine its significance in in the context of this thesis.

According to Lopes et al. (2017), information system is a set of interrelated elements that collect (or retrieve), process, store, and distribute information that supports decision making and control in an organization (Valeri \& Baggio, 2020a; 2020b). Information systems can also help executives and staff analyze problems, visualize complex issues, and create new products. Companies use different information systems to meet their different needs. This is because there are different levels of management within a business. These levels are: Level of Strategy, Level of Administration, Knowledge Management Level, and Function-Process Level (Rutherford \& Fallon, 2007).

Based on these levels the activities supported by these respective information systems are as follows: Advertisement ( Marketing ) and Sales, Production, Financial/Accounting, Human Resources Management.

To support all of the following activities, one type of system is not sufficient, therefore the information systems targeted at small and medium-sized enterprises, including hotel businesses, can be divided into the following categories, as presented and analyzed below (Laudon \& Laudon, 2004):

Function/Procedure Level System: This system allows the tracking of keyprocesses / functions that take place within a business. The Key processes / functions using information systems may include sales, receipts, payroll management, material flow, among others. The role of this system is to track and record the various transactions.

Knowledge Management System: This system has the role of ensuring that new knowledge about the processes and activities of the organization is recorded and maintained, and that existing knowledge is appropriately shared and used by management.

Management Level System: This system has the role of supporting control processes, monitoring of processes / activities, decision making and in general all administrative activities. Such systems provide the possibility of periodic reports on the above or ondemand reports.

Strategy Level System: This system provides the appropriate tools for shaping long-term planning / planning and business strategy.

Based on their functions, information systems can also be classified to the extent that they support the activities of the organization and the business. More specifically in a hotel business for booking and room management there are hotel business booking and activity management systems that support these businesses (Law \& Jogaratnam, 2005).

During the past years, we have seen many innovations launched in the tourist industry. One of them is the use of robots. The word Robot derives from the Slavonic word "robota", which stands for work. Indeed, it does not make a surprise that this work is associated with work. Asimov (1941) in his book "Three Laws of Robotics" has identified the three fundamental elements of robots which was that that (1) a robot must operate only to work and not to hurt human beings, (2) a robot must obey to the orders given from humans, unless those orders are contradicting the First Law of Robotics and (3) a robot has the right to protect itself, unless this contradict the First Law of Robotics. Since 1941, when Asimov wrote the three basic laws of Robotics, the use of robots has emerged mostly in the imagination of humans and less in practices though robots are widely use in manufacturing but not in services.

Nonetheless, it seems that recently there has been a breakthrough in the use of robots in the service sector (Markoff, 2016). It is important to remark that services include complex tasks which involved a high level of interaction between the robot (which is the service provider) and the customer. This means that the use of robots on services is much more complicated since it includes a high level of interaction with humans (Markoff, 
2016). In today's businesses, robots are used mostly for risky and dangerous tasks, such as to assemble cars.

The outcome is that the robots are replacing humans on the assembly lines resulting on economies of scales and on minimization of defects. However, when it comes on the service sector there is a criticism for the use of robots which is that the services cannot be standardized, while the quality of the services depends not only on the service provider but also on the quality of information and on the involvement of the customer (servuction). Therefore, the use of robots on services is a totally different concept from the use on mass production, while many individuals are arguing that humans are irreplaceable in services (Manyika et al., 2013).

On the other hand, none can stop the evolution and the development of new technologies. Innovations such as the Internet of Things, cloud computing and home robots are a reality and they widely used on households and businesses. Furthermore, many funds and investors have started funding projects related with high advanced technologies, including robotics. One of the reasons for investing to robotics is that because robots are able to reduce the labour costs up to $90 \%$, while on some cases robots are able to eliminate defects on production. An example of such investments is the Guangdong Province in China which has invested 154 billion dollars in projects related with robots. At the same time, more than $1 / 3$ of jobs in the UK are characterized by a high-risk of "roboticasation" which means that those jobs are subject of replaced from robots at some point in the future (Works, 2017). Works (2017) also ads that in the US it is expected that in the upcoming 15 years the $38 \%$ of jobs may be replaced from a robot. In addition, robots are widely used on housekeeping where companies such as Amazon are supplying the markets with robots, which are able to clean a house or any business facility, including hotels.

Another example is the case of Amazon in the US, which has used robots in its warehouses so to deliver the items, to package them and post them to the customers, while it is also using drones to deliver the products on its customers. However, despite of the funds given for further research and development in the robotic industry and the increasing of the sales volume of robots on many industries, still there are many ethical issues and dilemmas. For example, who is to blame in a case of an accident in a service? Is it going to be the company which delivers the service or the manufacturer of the robot or is it going to be the supervisor of the service and / or the programmer of the software used from the robot. In addition, there is an ethical issue regarding the replacement of employees and the loss of valuable jobs, which provide wealth for many people, especially the low ranking and unskilled labour (Lin et al., 2014). All those are issues, which the service and other industries will have to confront in the future.

\subsection{The Use of Robots in the Tourism Industry}

The use of robots in tourism is new and many of the studies are theoretical, and there is a significant lack of empirical studies and studies examining the impact of the use of robots on particular variables such as customer satisfaction and impact on employee job satisfaction.

One thing is to consider what consumer attitudes and perceptions are and how ready they are to receive the robots in hotels. Ivanov et al. (2018) state that more and more frequent use of robots in hotels can impede the resistance of both customers and hotel workers. Ivanov et al.'s (2018) survey was conducted in Russia and showed that consumers who seem to have a positive perception of the use of robots in the tourism industry are mainly young people, men who live in urban centers and have a positive attitude on the use of new technologies.

Research has also shown that consumers are more positive about using robots in informing visitors and less about having key roles in service such as housekeeping or services of particular importance. This means that based on the study by Ivanov et al. (2018), the consumers would prefer robots to have a supporting role in minor services. A study conducted 
from Tussyadiah and Park (2018) in a sample of tourists from the UK and America has shown that tourists have particular concerns about the use of robots in hotels, although this is why they appear to be satisfied with these services. The elements that will have a positive impact on consumers' perceptions of the experience they have with interacting with robots within a hotel is that the robot has human characteristics and behaviors. The second element is security.

It important to remark that a tourist wants to make sure that the robot does what it needs to do without compromising the safety of visitors. Stringam and Gerdes (2017) state that automating hotel services using robots aims to reduce running costs and outsourcing some services, such as cleaning or welcoming robots that are theoretically not they may be mistaken or influenced by particular factors that affect the employee delivering the service, such as fatigue, dissatisfaction with his work, or some inattention that may lead to an error. These are elements that can be avoided using robots and thereby increase the level of service provided by hotels and make better use of human resources. At this point, Murphy et al. (2017) point out that this is a very slim point and surely the data will change constantly as more robots are being developed in hotels and the public is becoming more familiar, the less credibility and ratings will be reduced. Another factor is the impact on job satisfaction. Since the use of robots is limited, it is expected and related research will be limited.

Lee and Baker (2017) refer to the fact that the use of robots in hotels may scare some of the employees but on the other hand, workers are familiar with new technologies and accept that a robot can do part of their work. In fact, in many cases employees see positively that some routine processes can be automated, such as to welcome the customers on the reception. Ivanov and Webster (2017) reported that the use of robots in hotels should be treated like any organizational change. This means that staff should be informed and involved in the whole process. In addition, proper staff training will help them work in harmony with the robots as well as redefine jobs.

Therefore, hotel management should pay equal attention to both customers and employees in order to improve the services provided (Kazandjieva \& Filipova, 2018). The use of robots can have a positive impact on earnings of the units as well as the cost of capital replaces labor costs and, at the same time, it requires training for workers so to acquire new skills. Empirical evidence derives also from the research made from Kuo et al. (2017) who have examined the case of the use of robots in Taiwan.

The outcome was that are some drivers in the environment which promote the use of robots. Those drivers include the aging of the population and advances in technologies which are increasing the demand for the use of robots. An interesting research has been made from Mende et al. (2019) who have examined the interactions between consumers and HSR (Humanoid Service Robots). Their paper concludes on the fact that it is uncertain whether this interaction will have a positive or a negative impact and what consequences it may trigger for the hotel industry. Their empirical findings have mentioned the fact that the use of HSR is favoured from consumers who want to purchase status goods and they seek social affiliation. Nonetheless, there is a need for more research on this field. At this point, Lu et al. (2019) have developed the multi-dimensional Service Robot Integration Willingness (SRIW) Scale. This is the first instrument of research which has been developed exclusively for the purpose for measuring the utilization of robots in services and especially on tourism. Another interesting insight has been provided from Zhong and Verma (2019) where their findings derive from a study of guests which occurred in 88 hotels in China which have installed robot-assisted services.

The participants have claimed that the robots were used for some basic functions such as for turning on or off the TV and the lights. On some case they were used for cleaning the rooms and on F\&B services. During the research the authors identified a number of problems caused from the use of robots such as not recognizing the commands and 
problems with the software used from the robots. On the aspect of the expectations that the guests have over what services to use, the answers were to use the robots on food distribution, delivering the goods, on the reception for the check-in/out and on infodesks where they will provide the guests with the necessary information regarding the destination and the hotel's services.

Overall, Zhong and Verma (2019) claimed that robots have been used from a number of hotels in China, but still there is lot of space for improvements on their use. In other researches, Chiang et al. (2019) have used the Kano model so to examine the satisfaction and the expectations of guests of hotels in Taiwan. One of the findings of this research was the guests favour the use of innovations from hotels.

The use of robots was tracked only in a small number of participants, however those who have experienced the use of robots had a positive experience and they have high expectations from the quality of services that the robtos will offer. At this point, it is Kuo et al. (2017) who have noted the gap in the existing literature regarding the intentinos to use the robots from the personnel and the guests. Kuo et al (2017) also remarked that the use of new technologies is highly valued from the guests, although for the use of robots is considered as an opportunity to leverage the service quality of hotels. Kuo et al. (2017) also discussed the use of robotics services to help restaurants handle seasonal employee and labor use. While the use of new technologies is highly valued in the hotel industry, this topic has not been extensively discussed in the field of hospitality research.Other researchers, such as Works (2017), Ivanov et al. (2019) and Ivanov and Webster (2019 a,b) indicate that some hotels, mostly found in technologically advanced nations such as Japan and Korea, have adopted the use of robots on some core services with success while the the guests and the personnel expect that the robots will leverage the quality of services and they will reduce the errors made during the delivery of the front-line services. This will contribute in an improvement on the quality of services.

Another argument for the use of robots is given from Li (2019), who indicates that the ageing population the western countries and on other key destinations such as Japan, means that there may be a shortage of workforce. This can be solved with the use of robots on front office services. As it is already claimed, the use of robots is something new for the hospitality sector; hence there is a need to provide empirical evidence so to better understand this phenomenon.

Ivanof et al. (2020) have used triangulation in a sample made from hotel managers in Bulgaria. The findings of Ivanov et al. (2020) indicate that hotel managers would like to use robots on dangerous and dull tasks in hotels, while human employees would be rather used on tasks which require soft skills and emotional intelligence. An important finding in this research is that the hotel managers regard that robots will decrease service quality of the hotels and that human workforce is much more valuable than robots; for this reason they seem not to favour the use of robots on their premises and they do no have the intention to use robots especially on risky tasks, though a meta-analysis made from Belias (2020b) argues that robots may leverage service quality of hotels and that the hotel managers and employees shall have high expectations.

A research made from $\mathrm{Xu}$ et al. (2020) indicate that the use of robots has pros and cons for the hotels. The advantages are the robots are expected to increase efficiency and productivity, while the disadvantages are the use of robots is expected to increase the operation costs, it may create skill deficits and it requires a significant change on the culture and the structure of the hotel.

Similar researches seem to produce mixed feelings for the use of robots since they may improve some services but they can not replace the workforce, especially in terms of soft skills and how an employee will tackle with the guest's requirements and problems that may appear (Amorim, 2020, Choi et al. 2020; Yu, 2020). The existing research indicates that the use of robots can take place mostly on some routine / secondary functions of the hotel such as 
to switch off the television or to provide information about the guests, while the guests seem to favor the use of robots.

On some cases the robots are used for housekeeping services. A critical issue which has been a subject of discussion on the most recent publications is that robots may improve the efficiency of the hotel's services but they are not able to replace human workforce. This is due of the fact that the employee's soft skills, knowledge, experience, problem solving skills and emotional intelligence are human assets that robots cannot replace. This creates several concerns regarding the effectiveness and the feasibility of using robots on hotels. Of course, most of the publications rely not on the field research but mostly on assumptions made from the participants.

The limited use of robots on hotels leads to significant lack of empirical evidence based on the actual use of robots from hotels. From the above, it is understood that from a critical perspective surely there is a lack of empirical research while is due of the limited use of robots from hotels but also on the fact that the use of robots is something new. In addition, from the findings of the existing publications it seems that there are many debates and arguments in and against the use of robots.

That is why the authors proceeded with the development of a unique research model which will allow the academic and practitioners to have a better understanding of the use of robots. At this point it should be noted also that there is a research gap in the acceptance of robots $\alpha$ by the public and employees in hotel units, while ther are different views on the impact on robots on services quality (ie. Belias, 2020b and Ivanov et al. 2020) while affects the intention to use robots. For this reason, the authors have constructed a research model which may fill in the existing gap.

\subsection{The Proposed Research Models}

From the previous lines it is undertstood that there are some research gaps. Indeed, authors such as Ivanov and Webster (2017) have noted that while cnosumers have the intention to use robos, but also that consumers trust robots (Tussyadiah et al, 2020; Qiu et al., 2020), there is a need to better understand what are the factors which will convince the conumers - and the personnel of the hotels - to use robots (Tussyadiah et al, 2020). Furthermore, there is evidence that robots contribute to service quality (Belias, 2020a). Even if there is some evidence, still there is a research gap when it comes in the views of hotel managers and employees, while most of the current researches (such as Ivanov et al., 2019; Tussyadiah et al, 2020) focus only on consumers but also they avoid to compare the impact of different dimensions of the use of robots, such as the intention to use along with the effect on service quality.

The proposed model has focus on two issue key directions. The first one is measurement of the intentions to use the robots and the second one are the expectations of the users from the quality of the services. Before the presentation of the model, it is important to mention the similar researches with emphasis on where they agree and where they disagree.

On the aspect of the intentions to use, authors such as Ivanov (2018) and Ivanov and Webster (2017) have mentioned that consumers have a positive stance for the use of robots and they have the intention to use them, while Tussyadiah et al. (2020) argue that some tourists are hesitant with the idea of using robots on services. In addition to this, Tussyadiah et al. (2020) claim that there is a need for further research on this issue so to clarify the intentions to use and what are the drivers of those intentions.

Rergarding the impact of robots on service quality, Chiang and Trimi (2020) have argued that guets claim robots may have a positive impact on the service quality of hotels. However, Belias (2020) have mentioned that the the personnel working on hotels does not have a clear view on whether robots can a positive impact on the service quality of hotels, something that 
is mentioned also from Zhong et al. (2020) who have argued that there is a need for more research on this topic.

Based on the above literature, there is a need to develop a research framework which will associated the intention to use robots and the measurement of the expectations of the customers from the quality of the services provided from robots. The related literature indicates that while the consumers tend to have a positive intention, tourist professionals are not so determined to use robots. Also, regarding the expectations from service quality, there is a need for more research, while the guests seem to have higher expectations than the hotel employees. Furthermore, there is a need to examine the possible association between the intentions to use and the impact that it has on the expectations of the customers from the quality of the services provided from robots. Therefore, this needs to develop a research framework and a data collection tool which will be used in a upcoming research.

The proposed research model has relied on the work of $\mathrm{Wu}$ and Wang (2005) who developed a model for the consumer intentions on mobile technologies. This model has been adjusted for the needs of the current research. In addition to this, the model has also used the SERVQUAL model which was developed from Parasuraman et al. (1985). The data collection tool is made from three parts which the following:

- Measurement of the intentions to use the robots adopted from the research made from $\mathrm{Wu}$ and Wang (2005), which was considered a very reliable instrument of research.. The intention questionnaire concerns factors which affect the intention such as the cost, ease of use, perception, compatibility and intentionality.

- The measurement of the expectations of the customers from the quality of the services provided from robots as expressed from the SERVQUAL questionnaire. This questionnaire tries to identify the five potential gaps / dimensions from the use of the robots on services (Parassuraman et al., 1985). Those are the particulars, reliability, response, security and empathy.

\section{Conclusion, Implications, and Limitations}

This paper has discussed issues related with the use of robots on hotels and the development of a research model. The literature review indicated that there is a gap in the existing literature. It it important to stress the fact that the robots have been used on some five-star hotels found mostly in Japan and Korea, and few hotels in the rest of the world. This means that the data collected from a primary research is limited and that many researches focus on the perceptions of participants who have not used robots yet. This means that there is enough space for future research on this field.

The researcher has given emphasis on developing a research model which will measure the possible association between the intentions to use and the impact that it has on the expectations of the customers from the quality of the services provided from robots. The existing research indicates two key issues. First of all that most (but not all of them) of the consumers have a positive intention to use robots and that they expect that robots will have a positive impact on service quality, while the same does not apply for the employees who are not so so positive; actually some are negative on the intention to use robots and its impact on service quality. A point where there is a consensus is the lack of empirical research.

The authors have concluded with the development of a model. The model is proposed to be used on several hotels so to measure and understand the intention of the guests and of the employees to use robots. The data which will derive from this research will help the academia and practitioners to better understand how robots can used from the hotel and tourist sector. This research is currently under progress in Greece and soon the authors will publish the results of this research. The advantage of this model is that the data is collected from research instruments that have been used on previous researches with high reliability, while the SERVQUAL model is the most common model used for measuring service quality. On the 
other hand, the limitation of this model is that is has not being used yet, hence surely it may require some amendments. Also, the case of robots is something ne and this means that many participants do not have sufficient knowledge and experiences so to develop a solid view on this issue. Therefore, there will be a need for several researches which will occur during the course of time and as long as the use of robots on hotel will increase.

\section{References}

Amorim, M. (2020). Service Robots in the Hospitality Industry: An Exploratory Literature Review. In Exploring Service Science: 10th International Conference, IESS 2020, Porto, Portugal, February 5-7, 2020, Proceedings (Vol. 377, p. 174). Springer Nature. https://doi.org/10.1007/978-3-030-38724-2_13

Asimov, I. (1941). Three laws of robotics. London: Runaround.

Belias D. (2020b). Examination of the Current Literature on How Robots Can Contribute on Hotel Service Quality. In: Kavoura A., Kefallonitis E., Theodoridis P. (eds) Strategic Innovative Marketing and Tourism. Springer Proceedings in Business and Economics. Springer, Cham. https://doi.org/10.1007/978-3-030-36126-6_92

Belias, D. (2019a). Entrepreneurship in the age of digital tourism; the future prospects from the use of robots. Malopolska Journal. (Special Issue: Entrepreneurship theory and practice: current trends and future directions). 42(2), 89-99.

Belias, D. (2019b). Robots on the tourist industry; a review for future research directions Special Issue on: Digital Transformation in the Tourism Industry. European Journal of Tourism Research. (Article in Press).

Belias, D. (2020a). Research Methods on the Contribution of Robots in the Service Quality of Hotels. In Strategic Innovative Marketing and Tourism (pp. 939-946). Springer, Cham. https://doi.org/10.1007/978-3-030-36126-6_104

Belias, D., \& Varelas, S. (2019). To Be or Not to Be? Which Is the Case with Robots in the Hotel Industry?. In Strategic Innovative Marketing and Tourism (pp. 935-941). Springer, Cham. https://doi.org/10.1007/978-3-030-12453-3_108

Chiang, A. H., \& Trimi, S. (2020). Impacts of service robots on service quality. Service Business, 14(3), 439-459.

Chiang, C. F., Chen, W. Y., \& Hsu, C. Y. (2019). Classifying technological innovation attributes for hotels: an application of the Kano model. Journal of Travel \& Tourism Marketing, 36(7), 796-807. https://doi.org/10.1080/10548408.2019.1575786

Choi, Y., Oh, M., Choi, M., \& Kim, S. (2021). Exploring the influence of culture on tourist experiences with robots in service delivery environment. Current Issues in Tourism, 24(5), 717-733.

Giannoukou, I., \& Beneki, C. C. (2018). Towards sustainability performance management system of tourism enterprises: a tourism sustainable balanced scorecard framework. International Journal of Global Environmental Issues, 17(2-3), 175-196.

Ivanov, S. (2020). The impact of automation on tourism and hospitality jobs. Information Technologies \& Tourism, 22, 205-215.

Ivanov, S. H., Gretzel, U., Berezina, K., Sigala, M., \& Webster, C. (2019). Progress on robotics in hospitality and tourism: A review of the literature. Journal of Hospitality and Tourism Technology, 10(4), 489-521.

Ivanov, S., \& Webster, C. (2017). Designing robot-friendly hospitality facilities. Proceedings of the Scientific Conference "Tourism. Innovations. Strategies", 13-14 October 2017, Bourgas: Bulgaria.

Ivanov, S., \& Webster, C. (2019). Robots in tourism: A research agenda for tourism economics. Tourism Economics, retrieved from https://www.researchgate.net/profile/Stanislav_Ivanov/publication/336236406_Robots_i 
n_tourism_A_research_agenda_for_tourism_economics/links/5e9b2820a6fdcca7892433 f8/Robots-in-tourism-A-research-agenda-for-tourism-economics.pdf [27/6/2020].

Ivanov, S., Gretzel, U., Berezina, K., Sigala, M., \& Webster, C. (2019). Progress on robotics in hospitality and tourism: a review of the literature. Journal of Hospitality and Tourism Technology, 10(4), 489-521. https://doi.org/10.1108/JHTT-08-2018-0087

Ivanov, S., Seyitoğlu, F., \& Markova, M. (2020). Hotel managers' perceptions towards the use of robots: a mixed-methods approach. Retrieved from https://www.researchgate.net/publication/342182167_Hotel_managers'_perceptions_tow ards_the_use_of_robots_a_mixed-methods_approach [27/6/2020].

Ivanov, S., Webster, C. \& Garenko, A. (2018). Young Russian adults' attitudes towards the potential use of robots in hotels. Technology in Society, 55, 24-32.

Kapiki, S., \& Fu, J. (2015). E-Hospitality Strategies Enhancing Competitiveness: Evidence from China and Central Macedonia, Greece. Chapter, 10, 165-190.

Katou, A. A., \& Katsouli, E. F. (2019). The Relationship Between Competitiveness-Driven Factors and Travel and Tourism Policy: A Multilevel Study. In Handbook of Research on International Travel Agency and Tour Operation Management (pp. 14-29). USA: IGI Global.

Kavoura, A. (2021). Two to Tango: Entrepreneurs and Robots' Users in Hospitality Service Innovation. In Service Excellence in Tourism and Hospitality (pp. 111-131). Springer, Cham.

Kazandjieva, V. I., \& Filipova, H. P. (2018). Customer's perception assessment of techrelated innovations in tourism. Izvestiya, 1, 5-20.

Kroenke, D. M. (1990). Management information systems. USA: McGraw-Hill, Inc.

Kuo, C. M., Chen, L. C., \& Tseng, C. Y. (2017). Investigating an innovative service with hospitality robots. International Journal of Contemporary Hospitality Management, 29(5), 1305-1321. https://doi.org/10.1108/IJCHM-08-2015-0414

Laudon, K. C., \& Laudon, J. P. (2004). Management information systems: Managing the digital firm. New Jersey: Pearson.

Law, R., \& Jogaratnam, G. (2005). A study of hotel information technology applications. International Journal of Contemporary Hospitality Management, 17(2), 170-180. https://doi.org/10.1108/09596110510582369

Lee, M., \& Baker, M. A. (2017). Technology, customer satisfaction and service excellence. Service Failures and Recovery in Tourism and Hospitality: A Practical Manual, 83.

Lim, T. W. (2019). Case Study 1: Japan's Foreign Talent Policy and the Future of Robot Replacements. In Industrial Revolution 4.0, Tech Giants, and Digitized Societies (pp. 85-95). Singapore: Palgrave Macmillan.

Lin, P., Abney, K., \& Bekey, G. A. (2014). Robot ethics: the ethical and social implications of robotics. MA: The MIT Press.

Lopes, I. M., Pereira, J. P., \& Oliveira, P. (2017). Definition of Information Systems Security Policies. In World Conference on Information Systems and Technologies (pp. 225-234). Springer, Cham. https://doi.org/10.1007/978-3-319-56541-5_23

Lu, L., C., R., \& Gursoy, D. (2019). Developing and validating a service robot integration willingness scale. International Journal of Hospitality Management, 80, 36-51. https://doi.org/10.1016/j.ijhm.2019.01.005

Manyika, J., Chui, M., Bughin, J., Dobbs, R., Bisson, P., \& Marrs, A. (2013). Disruptive technologies: Advances that will transform life, business, and the global economy (Vol. 180). San Francisco, CA: McKinsey Global Institute.

Markoff, J. (2016). Machines of loving grace: The quest for common ground between humans and robots. USA: HarperCollins Publishers. 
Mende, M., Scott, M. L., van Doorn, J., Grewal, D., \& Shanks, I. (2019). Service robots rising: How humanoid robots influence service experiences and elicit compensatory consumer responses. Journal of Marketing Research, 56(4), 535-556.

Murphy, J., Hofacker, C., \& Gretzel, U. (2017). Dawning of the age of robots in hospitality and tourism: Challenges for teaching and research. European Journal of Tourism Research, 15, 104-111.

Parasuraman A., Zeithaml V.A. \& Berry L.L. (1985). A conceptual model of service quality and its implications for future research. Journal of Marketing, 49(4), 41-50. https://doi.org/10.1177/002224298504900403

Qiu, H., Li, M., Shu, B., \& Bai, B. (2020). Enhancing hospitality experience with service robots: The mediating role of rapport building. Journal of Hospitality Marketing \& Management, 29(3), 247-268.

Rutherford, D. G., \& O'Fallon, M. J. (2007). Hotel management and operations. USA: John Wiley \& Sons.

Salminen, J., \& Milenkovic, M. (2020). "Her Name Was Chloe and She Delivers Stuff to Your Room" A Qualitative Analysis of User Reviews of Hotels Using Robots. In Proceedings of the 11th Nordic Conference on Human-Computer Interaction: Shaping Experiences, Shaping Society (pp. 1-12).

Stringam, B. B., \& Gerdes, J. H. (2017, October). The Automation of Service in the Hotel Industry. In Global Conference on Services Management (GLOSERV 2017) (p. 293).

Tussyadiah, I. (2020). A review of research into automation in tourism: Launching the Annals of Tourism Research Curated Collection on Artificial Intelligence and Robotics in Tourism. Annals of Tourism Research, 81, 1-44.

Tussyadiah, I. P., \& Park, S. (2018). Consumer Evaluation of Hotel Service Robots. In Information and Communication Technologies in Tourism 2018. Cham: Springer, 308320. https://doi.org/10.1007/978-3-319-72923-7_24

Tussyadiah, I. P., Zach, F. J., \& Wang, J. (2020). Do travelers trust intelligent service robots?. Annals of Tourism Research, 81(C), 1-43.

Tussyadiah, I. P., Zach, F. J., \& Wang, J. (2020). Do travelers trust intelligent service robots?. Annals of Tourism Research, 81, retrieved from https://www.tussyadiah.com/Do\%20we\%20trust\%20robots_TussyadiahZachWang_Fina l.pdf [13/02/2021]

Valeri, M. \& Baggio, R. (2020). Social network analysis: organizational implications in tourism management. International Journal of Organizational Analysis, Vol. 29 No. 2, pp. 342-353.

Valeri M., \& Baggio R. (2020b). Italian tourism intermediaries: a social network analysis exploration. Current Issues in Tourism, 1-14. https://doi.org/10.1080/13683500.2020.1777950

Valeri M., \& Baggio R. (2020c). A critical reflection on the adoption of blockchain in tourism. Journal Information Technology and Tourism, 1-12. https://doi.org/10.1007/s40558-020-00183-1.

Webster, C. (2019). Halfway there: the transition from 1968 to 2068 in tourism and hospitality. Zeitschrift für Tourismuswissenschaft, 11(1), 5-23.

Wood-Harper, A. T., Antill, L., \& Avison, D. E. (1985). Information systems definition: the Multiview approach. UK: Blackwell Science Ltd.

Works, R. (2017). The impact of technology on labor markets. Monthly Labor Review, 1-2.

Wu, J. H., \& Wang, S. C. (2005). What drives mobile commerce?: An empirical evaluation of the revised technology acceptance model. Information \& Management, 42(5), 719-729. https://doi.org/10.1016/j.im.2004.07.001

$\mathrm{Xu}$, S., Stienmetz, J., \& Ashton, M. (2020). How will service robots redefine leadership in hotel management? A Delphi approach. International Journal of Contemporary 
Hospitality Management. 32(6), 2217-2237. https://doi.org/10.1108/IJCHM-05-20190505

$\mathrm{Yu}$, C. E. (2020). Humanlike robots as employees in the hotel industry: Thematic content analysis of online reviews. Journal of Hospitality Marketing \& Management, 29(1), 2238. https://doi.org/10.1080/19368623.2019.1592733

Zhong, L., \& Verma, R. (2019). Robot rooms: How guests use and perceive hotel robots. Cornell Hospitality Report, 19(2), 1-8.

Zhong, L., Sun, S., Law, R., \& Zhang, X. (2020). Impact of robot hotel service on consumers' purchase intention: a control experiment. Asia Pacific Journal of Tourism Research, 25(7), 780-798.

\section{Author Biography}

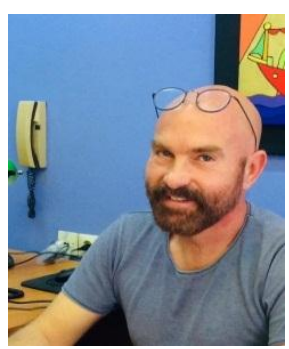

Dr. D. Belias is a Human Resource Management scientist. Holder of BSc, MSc, MEd, $\mathrm{PhD}$, University of Thessaly. He is an Assistant Professor in Organization and Services Management in the Tourist Market, of the Department of Business Administration, at the Universityof Thessaly, Greece. He is a Postdoctoral Research Fellow, in Organization and Services Management, of the Core Department, at the National and Kapodistrian University of Athens, Greece. Since 2017 he is a Lecturer in the Postgraduate Program of Tourism Business Administration and in the Graduate Program of Tourism Management, at the Hellenic Open University. He is currently a member in many scientific and professional bodies.

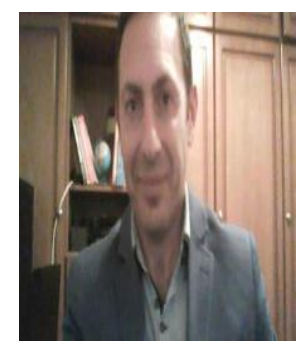

Dr. Labros Vasiliadis is Assistant Professor of Marketing Management at the Core Department of National and Kapodistrian University of Athens, Greece. His scientific research interests mainly focus on strategic marketing management, services and business strategy. 